\title{
A MODIFIED BACK-TO-BACK CURRENT SOURCE CONVERTER AND ITS APPLICATION TO WIND ENERGY CONVERSION SYSTEMS
}

\begin{abstract}
The back-to-back (BTB) converter is used in power conversion applications such as machine drives, wind energy conversion systems (WECS), uninterruptible power supplies, and HVDC transmission systems. Various topologies have evolved around voltage source converters and current source converters (CSC) in an attempt to meet various design and reliability constraints. This paper proposes a new CSC based BTB converter suitable for WECS application. The proposed configuration addresses the main drawbacks of the conventional BTB current source converters, such as the over-voltage frequently experience by switches during commutation. The inverter side converter has zero switching losses. The proposed WECS offers the following advantages: simple and easy control; reduced switching frequency, and maximum power-point tracking with controllable grid active and reactive power. Avoltage ride through (LVRT) solution is also provided in the proposed WECS. PSCAD/EMTDC simulation is used to assess the steady-state and dynamic behaviours of the proposed system under different operating conditions and during LVRT. Experimental results allow steady-state and dynamic behaviour assessment of the proposed system under different operating conditions.
\end{abstract}

Index Terms - wind energy conversion system, current source inverter and maximum power tracking.

\section{INTRODUCTION}

Wind energy is a growing and promising renewable energy source for small and large-scale energy harvesting. Wind energy conversion systems (WECS) can be classified into two types: 1) fixed-speed where a squirrel-cage induction generator is used and 2) variable-speed where a doubly fed induction generator (DFIG) or variable-speed permanent magnate synchronous generator (PMSG) with a full scale back-to-back (BTB) convert is employed. Variable speed WECS is attractive due to increasing the kilowatt-hour production of wind farms, higher overall efficiency, and lower mechanical stress [1,2].

Both of the aforementioned variable speed WECS use BTB converters. A PMSG-based wind turbine-generator consists of a generator and grid side converters, and must be connected and decoupled through an energy storage element such as a capacitor for a voltage source converter (VSC) or inductance for a CSC[3]. For small-scale power, a diode rectifier followed by a dc chopper is used to achieve variable speed operation and maximum power point tracking (MPPT), while the grid side VSC is used to inject the generated power into the grid [4-6]. The application of the two-level BTB VSC is studied in $[7,8]$ and adopted in earlier WECS generations. The authors in [1] proposed a reduced switch count BTB VSC to improve reliably and overall performance, and this BTB consists of a three-phase three-switch PWM buck-type rectifier in series with a Z-source inverter. The configuration provides high reliability and harmonic-free characteristics in both the generator and grid sides. However, the Z-source inverter in [1] uses four passive elements in the dc-link, which increase the overall system size, weight and cost. In [9, 10], energy-storage is eliminated from the dc-link using a matrix converter. In multi megawatt wind turbine-generators that require a higher dc link voltage, a multilevel neutral-point-clamped converter is proposed in $[11,12]$ as means to avoid the series connected of power electronics devices, and decrease the voltage stress on the machine and interfacing transformer insulation. A BTB CSC configuration for a high power wind turbine is shown in [13].

With increased penetration of the wind power into the utility, its disconnection hence voltage dip during a grid ac fault, has become unacceptable in terms of system stability. As a result, grid codes have become much stricter for grid connected WECS, and demand that they remain connected to the grid and supply reactive power with a given voltage dip profile [14-16].

During a grid fault, the grid side converter of a VSC based WECS will not be able to deliver the active power produced by the wind turbine-generator to the grid. This power will over-charge the dc-link capacitor, producing an overvoltage dc-link condition, thus exposing power electronics converters to increased risk of overvoltage failure [17]. This problem is solved in VSC based WECSs by installing an energy dumping resistor in series with a power electronics switch across the dclink capacitor, to dissipate the power that cannot be delivered to the grid $[15,18]$. An alternative solution is to store the active power surplus in the inertia of the turbine generator to achieve the LVRT requirement [16]. A similar solution is adopted for the CSC in [19]

This paper proposes a medium speed drive train WECS that uses a new CSC based BTB converter configuration, as shown in Fig.1. This configuration addresses the main drawbacks of conventional BTB current source converters such as the overvoltage frequently experience by switches during commutation. Additionally, it offers the following advantages: simple and easy control; sinusoidal ac currents with high power factor at both ac sides with reduced switching frequency; inverter side zero switching losses; and the rectifier side soft start-up and soft shutdown. The viability of the proposed WECS is demonstrated using simulations and experimentation, during normal operation and ac network 


\section{CIRCUIT ANALYSIS AND MODELING}

\section{A. Proposal WECS description}

Fig.1 shows the proposed variable speed wind energy conversion system based on BTB current fed converters. It consists of a three-phase permanent magnet synchronous generator (PSMG), buck-boost converter, and a pulse width modulated current source inverter at the grid side. In the wind side converter (buck-boost stage), the series switch $S_{r}$ in Fig.1 is used to adjust the power flow by controlling the average dc current in the link inductor $L_{d c}$.

The proposal BTB converter has two operating modes. The first mode charges the dc-link inductor $L_{d c}$ when the switch $S_{r}$ is ' $\mathrm{ON}$ '. In this mode, the dc-link inductance charging current is equal to the switch $S_{r}$ current, which is set by the input power from the PMSG through the three-phase bridge rectifier. During this mode the CSI input dc current $I_{i}=0$. The second mode is when switch $S_{r}$ is 'OFF'. The dc-link inductance $L_{d c}$ discharges, where the dc-link inductor current $I_{L}=I_{i}$ and the current in the switch $S_{r}$ is $I_{s}=0$. During the second mode no current enters the BTB converter, hence the C-filter $\left(C_{r}\right)$ makes the current seen by the generator continuous. The $\mathrm{C}$-filter also performs the general filtering role as in any current fed converter. Similarly, during the first mode, the CSI input dc-link current $I_{i}=0$, so the grid side Cfilter makes the grid current continuoues in addition to its general harmonic filtering role.

\section{B. Current source inverter}

For minimum switching losses, the grid side CSI in the proposed BTB converter is controlled using selective harmonic elimination (SHE), with three notches per quarter cycle to eliminate the 5th harmonics order; and from[20] the notch angle is $\Theta=18^{\circ}$. The switching frequency (fsr) of the switch $\mathrm{Sr}$ is $2.4 \mathrm{kHz}$ and grid frequency (fg) is $50 \mathrm{~Hz}$. The rectifier chop pulse resolution (SR) represents the relative width in degrees of one switching cycle of $\operatorname{Sr}\left(S R=\frac{360 f_{g}}{f_{s r}}\right)$ in one fundamental period. For fsr $=2.4 \mathrm{kHz}$ and $\mathrm{fg}=50 \mathrm{~Hz}, \mathrm{SR}=$ $7.3^{\circ}$. To ensure zero switching losses at the CSI, the switching instants of the CSI devices must coincide with zero input dclink Ii, which is determined by the modulation of the switch Sr. This requirement imposes the restriction on the ratio of the switching frequency of the switch Sr to grid frequency must be an integer multiple of 3 (in other words, integer number of pulses per 120o). Increasing the switching frequency of switch Sr improves the ability of SHE to eliminate more loworder harmonics, and decreases the dc-link inductance Ldc and C-filters at both ac sides. But it increases switching losses of switch Sr. Fig. 4 shows the inverter output current with one angle to eliminate a single harmonic order.

\section{PMSG model.}

The PMSG model is based in the $d q$-axis reference frame, where the q-axis is $90^{\circ}$ ahead of the $d$-axis. The PMSG is assumed to have uniformly distributed stator windings and the $d$-axis and $q$-axis synchronous inductances are equal, $L_{d} \approx L_{q} \approx L_{g}$. Saturation, eddy currents and core losses are neglected, and the resistances of the three-phase windings are equal. The steady-state voltage and equations are $[1,21,22]$ :

$$
\begin{aligned}
& v_{d g}=-R_{g} i_{d g}-p \psi_{d}+\omega_{e} \psi_{q} \\
& v_{q g}=-R_{g} i_{q g}-p \psi_{q}-\omega_{e} \psi_{d} \\
& T_{e}=\frac{2}{3} P \psi_{P M} i_{q g}
\end{aligned}
$$

The stator flux components are:

$$
\begin{aligned}
& \psi_{d}=L_{d} i_{d g}+\psi_{P M} \\
& \psi_{q}=L_{q} i_{q g}
\end{aligned}
$$

Where $\mathrm{v}_{\mathrm{dg}}, \mathrm{v}_{\mathrm{qg}}, \mathrm{i}_{\mathrm{dg}}$ and $\mathrm{i}_{\mathrm{qg}}$ are the $\mathrm{d}-\mathrm{q}$ components of the stator voltage and current,p is the differential operator, Rs is the stator resistance, $\omega_{\mathrm{e}}$ is the generator electrical angular speed, $\mathrm{Te}$ is the electromagnetic torque, $\psi_{\mathrm{PM}}$ is permanent magnet flux, and $\mathrm{P}$ is the number of pole pairs.

\section{Wind turbine modeling}

The wind turbine model, based on steady-state power characteristics, is described in [23, 24], where the output aerodynamic power of the wind turbine is:

$$
\begin{aligned}
& P_{t}=\frac{1}{2} \rho A C_{p}(\lambda, \beta) V^{3} \\
& \left.T_{t}=P_{t} / \omega_{t}=? \rho A C_{t} \lambda, \beta\right) V^{2} \\
& \lambda=\frac{\omega_{t} R_{t}}{v}
\end{aligned}
$$

where $\rho$ is the air density $(1.225 \mathrm{~kg} / \mathrm{m} 2), \mathrm{A}$ is the rotor swept area (m2), $C_{p}$ is the power coefficient, $v$ is the wind speed $(\mathrm{m} / \mathrm{s})$ and $\beta$ is the blade pitch angle $\left(^{\circ}\right), \omega_{\mathrm{t}}$ is the turbine rotor angular velocity ( $\mathrm{rad} / \mathrm{s}), \mathrm{C}_{\mathrm{t}}$ is the torque coefficient of the turbine, $R_{t}$ is the rotor radius ( $m$ ), and $\lambda$ is the tip speed ratio.

The power coefficient $C_{p}$ is a nonlinear function of tip speed ratio $\lambda$ and blade pitch angle $\beta$ for a constant wind speed. The power coefficient $\mathrm{Cp}$ is maximum at $\lambda$ opt and is calculated using a generic equation as shown in (9)where $\lambda \mathrm{i}$ is defined by:

$$
\begin{aligned}
& C_{p}=0.5176 \times\left(\frac{116}{\lambda_{i}}-0.4 \beta-5\right) \times e^{\frac{-21}{\lambda_{i}}}-0.006795 \lambda_{i} \\
& \lambda_{i}=\left[\frac{1}{\lambda+0.08 \beta}-\frac{0.035}{\beta^{3}+1}\right]^{-1}
\end{aligned}
$$

By solving equations (9) and (10) when $\beta=0, C_{p \max }$ (the maximum value of $C_{p}$ ) is found to be 0.48 and $\lambda_{\text {opt }}=8.1$. Equation (8) can be used to determine the optimal turbine speed $\left(\omega_{t(o p t)}\right)$ at each wind speed.

$$
\omega_{t(o p t)}=\frac{V \lambda_{o p t}}{R_{t}}
$$

The optimal generator speed $\left(\omega_{\text {opt }}\right)$ can be determined by multiplying the optimal turbine speed $\left(\omega_{t(o p t)}\right)$ by the gear box ratio (GBR).

$$
\omega_{o p t}=G B R \frac{V \lambda_{o p t}}{R_{t}}
$$




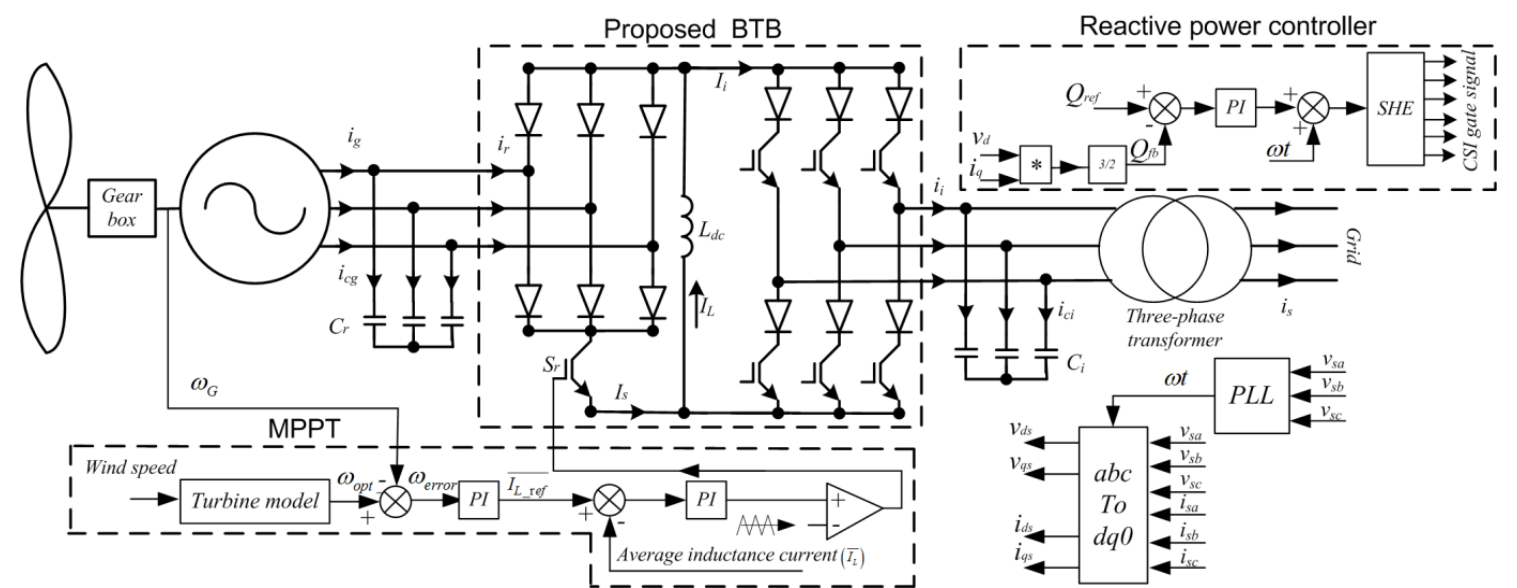

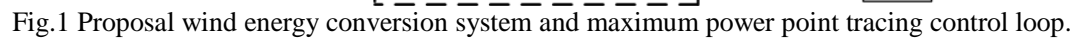

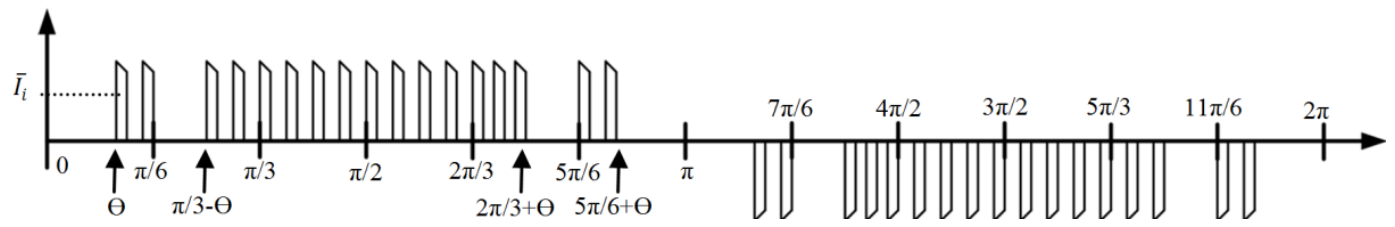

Fig. 2 Inverter wave form of half cycle with one angle

\section{CONTROL STRATEGY}

There are two main control loops in the proposal WECS first MPPT controller and grid reactive power controller.

\section{A. Maximum power point tracking controller}

The proposed MPPT control loop consists of two control loops, namely inner and outer loops as shown in Fig.1. The outer control loop detects the wind speed and used equation (12) to calculate the corresponding optimal generator speed $\omega_{\text {opt }}$. The speed regulator based on proportional-integral $(P I)$ control estimates the reference average dc-link inductance current $\overline{I_{L_{-} r e f}}$ for the inner control loop. The inner controller, which regulates $\overline{I_{L}}$, estimates the modulation index $\delta$ of the switch $S_{r}$, necessary to control the power flow from the wind generator into the grid, as will be illustrated in the subsequent analysis.

To establish the relationship between the powers delivered to the grid and the dc-link inductance current $\bar{I}_{L}$, and the relation between the dc-link inductance current $I_{L}$ and generator current, the active and reactive powers $\left(P_{g}\right)$ and $\left(Q_{g}\right)$ are expressed as:

$$
\begin{aligned}
& P_{g}=\frac{3}{2} i_{d s} v d s \\
& Q_{g}=\frac{-3}{2} i_{q s} v_{d s}
\end{aligned}
$$

where $v_{d s}$ is the $d$ component of the grid voltage $\left(V_{s}\right)$, assuming the grid voltage vector is aligned with the $d$-axis $\left(v_{q s}=0\right)$; and $i_{d s}, i_{q s}$ are $d$ and $q$ current components that the current grid side converter injects into grid.

Based on Fig. 3 the steady state equations that describe the ac side of the grid side converter are:

$$
\begin{aligned}
& v_{c i(d)}=R_{s} i_{s(d)}-\omega_{s} L_{s} i_{s(q)}+v_{s(d)} \\
& v_{c i(q)}=R_{s} i_{s(q)}+\omega_{s} L_{s} i_{s(d)}
\end{aligned}
$$

where $L_{s}$ and $R_{s}$ are the transformer leakage inductance and resistance, and $v_{c i(d)}$ and $v_{c i(q)}$ are the $d$ and $q$ components of the grid side filter capacitor voltage. Similarly, the filter capacitor current $i_{c i}$ can be expressed as:

$$
i_{c i(d)}=-\omega_{s} C_{i} v_{c i(q)}
$$

(17)

$$
i_{c i(q)}=\omega_{s} C_{i} v_{c i(d)}
$$

The current provided by the CSI $i_{i}$ is the sum of the grid current $i_{s}$ and the capacitor $C_{i}$ current $i_{c i}$. The CSI output current $i_{i}$ can be express as:

$$
\begin{aligned}
& i_{d i}=\left(1-\omega_{s}^{2} C_{i} L_{s}\right) i_{s(d)}-\omega_{s} C_{i} R_{s} i_{s(q)} \\
& i_{q i}=\left(1-\omega_{s}^{2} C_{i} L_{s}\right) i_{s(q)}+\omega_{s} C_{i}\left(v_{s(d)}+R_{s} i_{s(d)}\right)
\end{aligned}
$$

For modulation index $m=1$, as being considered in this paper, the average current at the CSI input $\bar{I}_{i}$ equals the peak fundament current of $I_{m i}$ (recall $I_{m i}=m \bar{I}_{l}$ ). The following equations are obtained:

$$
\begin{aligned}
& I_{m i}=\sqrt{\left(i_{d i}^{2}+i_{q i}^{2}\right)} \\
& \bar{I}_{i}=I_{m i}=\sqrt{\left(\left(1-\omega_{s}^{2} C_{i} L_{s}\right) i_{s(d)}-\omega_{s} C_{i} R_{s} i_{s(q)}\right)^{2}+}
\end{aligned}
$$

Assuming that the grid reactive power controller operates at unity power factor, $i_{q s}=0$, equation (22) reduces to:

$$
\overline{I_{i}}=\sqrt{\left(1-\omega_{s}^{2} L_{s} C_{i}\right)^{2} i_{d s}^{2}+\omega_{s}^{2} C_{i}^{2}\left(v_{d s}+R_{s} i_{d s}\right)^{2}}
$$




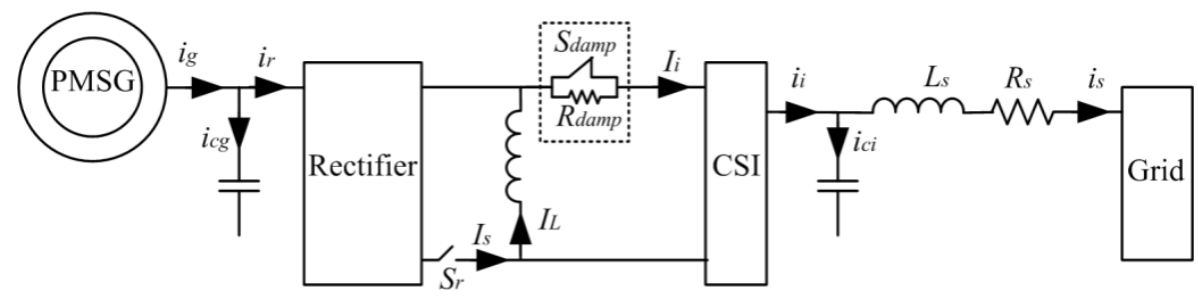

Fig.3 Single line diagram representation of the proposal WECS

Since the current entering the CSI $I_{i}$ is equals to the dc-link inductance current $I_{L}$ when the switch $S_{r}$ is off, the average dclink inductance current $\bar{I}_{L}$ can be of obtained from (24):

$$
\overline{I_{L}}=\frac{1}{(1-\delta)} \overline{I_{i}}
$$

Substitute (22) into (24) gives:

$$
\overline{I_{L}}=\frac{1}{(1-\delta)} \sqrt{\left(1-\omega_{s}^{2} L_{s} C_{i}\right)^{2} i_{s(d)}^{2}+\omega_{s}^{2} C_{i}^{2}\left(v_{s(d)}+R_{s} i_{s(d)}\right)^{2}}
$$

Combining equation (13) $\left(i_{d s}=\frac{P_{g}}{1.5 v_{d c}}\right)$ and (25) gives:

$$
\overline{I_{L}}=\frac{1}{(1-\delta)} \sqrt{\left(1-\omega_{s}^{2} L_{s} C_{i}\right)^{2}\left(\frac{P_{g}}{1.5 v_{s(d)}}\right)^{2}+\omega_{s}^{2} C^{2}\left(v_{d s}+R_{s} \frac{P_{g}}{1.5 v_{s(d)}}\right)^{2}}
$$

Equation (26) describes the relationship between $\bar{I}_{L}$, and $\delta$ (duty cycle of the switch $S_{r}$ ) and active power $P_{g}$ delivered to the grid. On this basis, this paper chooses to regulate the power flow between the two ac sides by controlling $\delta$.

Furthermore, the effect of varying $\delta$ (the modulation index of the switch $S_{\mathrm{r}}$ ) on the average dc-link inductance current $\bar{I}_{L}$ and generator current $i_{g}$ will be established.

The generator side $\mathrm{C}$-filter current can be derived as:

$$
\begin{aligned}
& i_{c g(d)}=C_{g}\left(p v_{g(d)}-\omega_{e} v_{g(q)}\right) \\
& i_{c g(d)}=C_{g}\left(p v_{g(q)}-\omega_{e} v_{g(d)}\right)
\end{aligned}
$$

The rectifier input current can be obtained by subtracting the capacitor current from the generator current. The steady state rectifier input current is shown in equations (29) and (30)

$$
\begin{aligned}
& i_{r(d)}=i_{g(d)}+\omega_{e} C_{g} v_{g(q)} \\
& i_{r(q)}=i_{g(q)}-\omega_{e} C_{g} v_{g(d)}
\end{aligned}
$$

The peak fundamental rectifier input current can calculated as follows:

$$
I_{r(p)}=\sqrt{\left(i_{r(d)}^{2}+i_{r(q)}^{2}\right)}
$$

To facilitate analysis of the rectifier input current, the dclink inductance $L_{d c}$ is assumed sufficiently large so that the dclink inductor current is constant (ripple free) and equals $\bar{I}_{L}$. Fig.4 shows rectifier input current during one fundamental cycle, and during one carrier cycle, where the switch $S_{r}$ operates with a constant duty cycle. The spectrum of the rectifier input current $i_{R}$ can be obtained using the double Fourier series in complex form [25]:

$$
i_{r(m n)}=\frac{1}{2 \pi^{2}}\left|\int_{\frac{\pi}{6}}^{\frac{5 \pi \pi}{6}} \int_{-\delta \pi}^{\delta \pi} I_{d} e^{j(m x+n y)} d x d y-\int_{\frac{7 \pi}{6}-\delta \pi}^{\frac{11 \pi}{6} \delta \pi} \int_{d}^{\delta} I_{d} e^{j(m x+n y)} d x d y\right|
$$

where $y=\omega_{0} t, x=\omega_{c} t, \omega_{0}$ and $\omega_{c}$ respectively represent fundamental and carrier frequencies in $\mathrm{rad} / \mathrm{s}$, and $n$ and $m$ are the orders of the baseband and carrier component harmonics.

The baseband harmonics of the rectifier input $i_{r}$ are computed by setting $m=0$ in (32), yielding:

$$
i_{r(0 n)}=A_{0 n}+j B_{0 n}=\frac{j 2 \sqrt{3} \delta I_{L}}{n \pi}
$$

Equation (33) is valid for all $n$ that represent odd and nontriplen harmonics; otherwise $i_{r(0 n)}=0 . A_{o n}=0$ and $B_{o n}=\frac{2 \sqrt{3} \bar{I}_{L}}{n \pi}$. The peak value of the rectifier input fundamental component $I_{r(p)}$ is obtained when $n=1$.

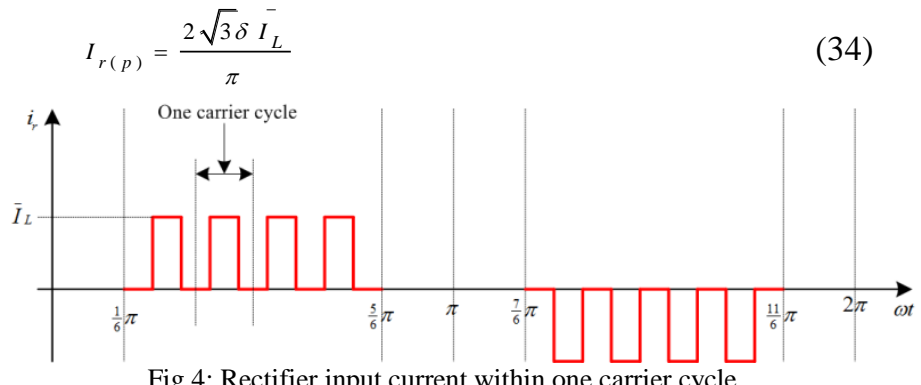

Fig.4: Rectifier input current within one carrier cycle.

After combining (29), (30), (31), and (34), the following expression results:

$$
\overline{I_{L}}=\frac{\pi}{2 \sqrt{3} \delta} \sqrt{\left(i_{g(d)}+w_{e} c_{g} v_{g(q)}\right)^{2}+\left(i_{g(q)}-w_{e} C_{g} v_{g(d)}\right)^{2}}
$$

From this analysis, the average dc-link inductance current $\overline{I_{L}}$ is controlled by changing the modulation index $(\delta)$ of switch $\mathrm{Sr}$,. Increasing the modulation index $\delta$ will increase $\bar{I}_{L}$, hence according to equations (31) and (34) the current generator will increase which will tends to increase the electromagnetic torque and decrease the turbine speed. Also according to equation (26) the active power delivered to the grid will increase. Decreasing the modulation index $\delta$ has the vice versa effect.

\section{B. Grid reactive power controller}

The reactive power controller in Fig. 1 is used to adjust the phase angle $(\alpha)$ between the grid voltage and current vector. The CSI injects into the grid based on the reactive power demand set point $\left(Q_{r e f}\right)$. Therefore, the required phase angle $(\alpha)$ for arbitrary reactive power is estimated using PI control 
as:

$$
\alpha=k_{p Q}\left(Q_{r e f}-Q\right)+k_{i Q} \int\left(Q_{r e f}-Q\right) d t
$$

where $k_{p Q}$ and $k_{i Q}$ are the proportional and integral gains of the reactive power controller. The estimated phase angle $(\alpha)$ from (36) is added to angle $\omega t$, which is obtained from the phase locked loop (PLL), and the resultant angle $\omega t+\alpha$ is used to provide the time base for the SHE algorithm. Calculation of $\alpha$ based on (36) is not the same as the CSI load angle ( $\Delta)$, which is given by (37). The load angle $\Delta$ is set indirectly by the amount of active power CSI exchange with the grid.

$\Delta=\tan ^{-1}\left(\frac{i_{i d}}{i_{i q}}\right)=\tan ^{-1}\left(\frac{\left(1-\omega_{s}^{2} L_{s} C_{i}\right) i_{d s}}{\omega_{s} C_{i}\left(v_{d s}+R_{s} i_{d s}\right)}\right)$

\section{SimUlations}

Table 1 summarises parameters used in simulations and experimental test rig of the proposal WECS, Fig.1.

\begin{tabular}{|c|c|c|}
\hline & Simulation & Experiment \\
\hline \multicolumn{3}{|c|}{ Wind turbine parameters } \\
\hline Rated power & $0.52 \mathrm{MW}$ & $2 \mathrm{~kW}$ \\
\hline $\begin{array}{l}\text { Rated wind } \\
\text { speed }\end{array}$ & $12.5 \mathrm{~m} / \mathrm{s}$ & $12.5 \mathrm{~m} / \mathrm{s}$ \\
\hline $\begin{array}{l}\text { Cut-in wind } \\
\text { speed }\end{array}$ & $4 \mathrm{~m} / \mathrm{s}$ & $4 \mathrm{~m} / \mathrm{s}$ \\
\hline $\begin{array}{l}\text { Cut-out wind } \\
\text { speed }\end{array}$ & $25 \mathrm{~m} / \mathrm{s}$ & $25 \mathrm{~m} / \mathrm{s}$ \\
\hline Rotor diameter & $1.8 \mathrm{~m}$ & $1.8 \mathrm{~m}$ \\
\hline Rotor area & $10178 \mathrm{~m}^{2}$ & $10.2 \mathrm{~m}^{2}$ \\
\hline Gearbox ratio & $1: 5.7$ & $1: 2.8$ \\
\hline \multicolumn{3}{|l|}{ Grid parameters } \\
\hline Voltage & $3.3 \mathrm{kV} \mathrm{L-L}$ & $140 \mathrm{~V}$ L_L \\
\hline Frequency & 50 & 50 \\
\hline \multicolumn{3}{|c|}{ Grid connected transformer } \\
\hline Power & $0.5 \mathrm{MW}$ & $2.0 \mathrm{~kW}$ \\
\hline Voltage & $3.3 / 1.65 \mathrm{kV} \mathrm{L-L}$ & 400/200V L-L \\
\hline \multicolumn{3}{|c|}{ Generator parameters } \\
\hline Rated power & $0.51 \mathrm{Mw}$ & $6.0 \mathrm{~kW}$ \\
\hline $\begin{array}{l}\text { Synchronous } \\
\text { inductance }\end{array}$ & $20 \mathrm{mH}$ & $35 \mathrm{mH}$ \\
\hline $\begin{array}{l}\text { Number of } \\
\text { Poles }\end{array}$ & 20 & 4 \\
\hline \multicolumn{3}{|c|}{ Converter parameters } \\
\hline $\begin{array}{l}\text { Generator side } \\
\text { Capacitor }\end{array}$ & $\begin{array}{l}200 \mu \mathrm{F} \mathrm{Y} \\
\text { connected }\end{array}$ & $\begin{array}{l}150 \mu \mathrm{Ff} \mathrm{Y} \\
\text { connected }\end{array}$ \\
\hline $\begin{array}{l}\text { dc-link } \\
\text { inductance }\end{array}$ & $10 \mathrm{mH}$ & $12.5 \mathrm{mH}$ \\
\hline $\begin{array}{l}\text { Grid side } \\
\text { capacitor }\end{array}$ & $\begin{array}{l}250 \mu \mathrm{F} \mathrm{Y} \\
\text { connected }\end{array}$ & $\begin{array}{l}100 \Delta \\
\text { connected }\end{array}$ \\
\hline
\end{tabular}

\section{A. Normal operation}

To assess the dynamic performance of the proposed WECS, its illustrative version in Fig.1 is simulated using PSCAD/EMTDC. The wind speed is varied from $6 \mathrm{~m} / \mathrm{s}$ to $10 \mathrm{~m} / \mathrm{s}$ through intermediate steps of $(8 \mathrm{~m} / \mathrm{s}$ and $12.5 \mathrm{~m} / \mathrm{s})$, and the results obtained are shown in Fig.5 and Fig. 6. Fig.5(a) shows wind PMSG generator speed follows the optimal speed provided by the MPPT as the wind speed varies. Fig.5(b) is presented to show a detailed viewed of the generator speed during transition from wind speed $8 \mathrm{~m} / \mathrm{s}$ to $12.5 \mathrm{~ms}$, where the generator speed is able track its optimal values precisely, with minimal transient and time lag. Fig.5(c) shows the power the CSI inverter exchanges with the grid as the wind speed varies according to the profile given. Fig.5(d) shows a detailed view of the power plot in Fig. 5(c) focused around the wind speed transition from $8 \mathrm{~m} / \mathrm{s}$ to $12.5 \mathrm{~ms}$. The proposal WECS controller decreases the grid power to decrease the mechanical torque provided by the generator during the wind speed change from $8 \mathrm{~m} / \mathrm{s}$ to $12.5 \mathrm{~m} / \mathrm{s}$. Decreasing the generator torque allows the wind turbine to build up speed faster and decreases the transient time during the speed change.

Fig. 6 shows a detailed view of the grid currents and phase ' $a$ ' voltage during the wind speeds equals to $(10 \mathrm{~m} / \mathrm{s}$ and 12.5 $\mathrm{m} / \mathrm{s}$ ), where the proposed WECS produces sinusoidal currents at grid with nearly unity power factor.

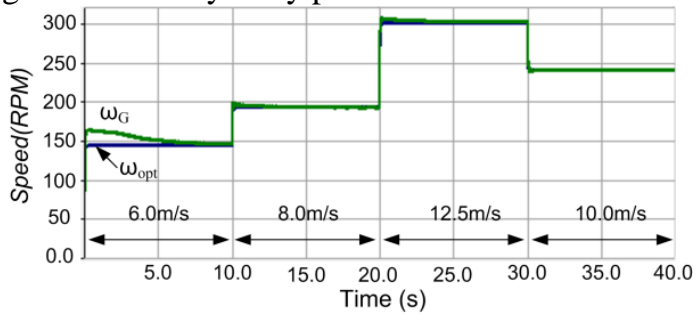

(a) Generator speed and optimal generator speed

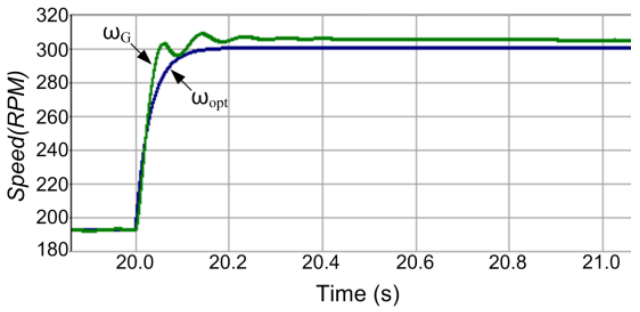

(b) A detailed view of the generator speed and optimal speed during changing in the wind speed from $8 \mathrm{~m} / \mathrm{s}$ to $12.5 \mathrm{~m} / \mathrm{s}$

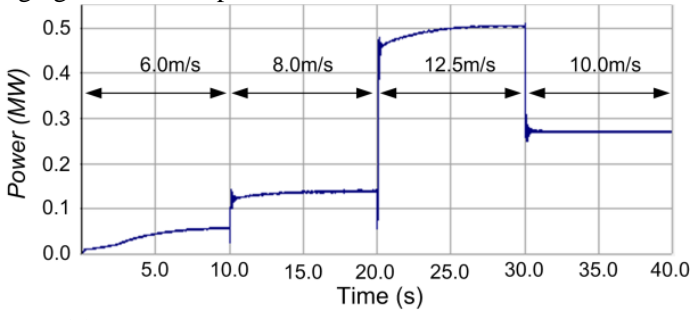

(c) Grid output power

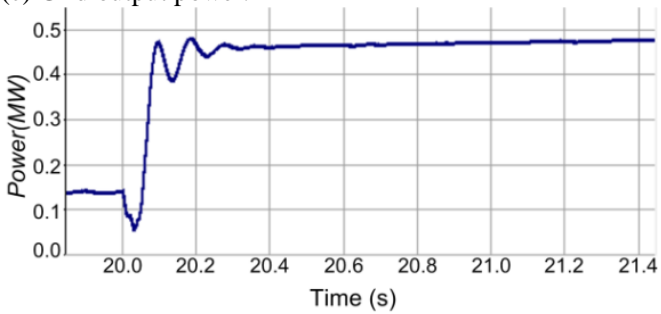

(d) A detailed view of grid output power during changing in the wind speed from $8 \mathrm{~m} / \mathrm{s}$ to $12.5 \mathrm{~m} / \mathrm{s}$.

Fig.5 Waveforms shows simulation results of the generator speed and the grid output power at different cases.

\section{B. Low voltage ride-through (LVRT) illustration}

This subsection investigates the fault ride-through capability of the proposed WECS during an ac network fault (The worst case fault is considered, namely a three-phase 
symmetrical fault in close proximity to the point of common coupling (PCC)). During the short-circuit fault, the grid voltage collapses to zero. As a result, the CSI cannot deliver to the grid, active power produced by the wind turbine. This will create significant power imbalance between the CSI ac and dc sides that may cause a massive increase in the dc-link inductor current $I_{L}$. Such over-current may pose damage risk to the CSI. In an attempt to improve the resiliency of the proposed WECS to such extreme faults, the power dissipation mechanism consists of a resistance with a power electronics shunting switch, as shown in Fig. 3. (A shunt dumping circuit parallel to $L_{d c}$ is an alternative.) During normal operation switch $\left(S_{\text {damp }}\right)$ is used to bypass the damping resistance $\left(R_{\text {damp }}\right)$. During grid short circuit, the proposal WECS temporary stores the active power surplus in the turbine-generator mechanical system inertia, while the dc-link inductances current $I_{L}$ is restrained by the LVRT mechanism as follow:

In the charging mode, if the dc-link inductance current $I_{L}$ reaches its maximum limit, the switch $S_{r}$ is turned off until the current $I_{L}$ reaches the lower band of the charging current. This will protect the generator side convert from over current, and provide the first part of protecting the dc-link inductor $L_{d c}$ from over current.

In the discharging mode, if the dc-link inductance $I_{L}$ reaches its upper limit, the switch $S_{\text {damp }}$ is turned off to insert the resistance $R_{\text {damp }}$ into the conduction path, preventing $I_{L}$ from increasing, thus protecting the CSI from over current. Whence the entire system is protected.

Although the proposed LVRT technique is simple, easy to implement, high reliability and durability, but the following drawbacks: extra hardware and continuous conduction loses on the switch $S_{\text {damp }}$ under normal operation. Another solution is to control the dc-link current by controlling the grid side converter as shown in[20], which can discussed in further researches.

In this simulation section, the proposed LVRT technique is tested during a three-phase grid short circuit close to the PCC, with a $150 \mathrm{~ms}$ fault duration. The switch $\mathrm{S}_{\mathrm{r}}$ is controlled with lower and higher bands of $0.43 \mathrm{kA}$ and $0.45 \mathrm{kA}$ respectively. The LVRT upper and lower current limits of 0.5kA and $0.45 \mathrm{kA}$ are adopted for $S_{\text {damp }}$. Fig.7 (a) shows the temporary generator over-speed as the three-phase ac fault creates power imbalance between the ac and dc sides. The active power that cannot be transferred into ac side is absorbed by the mechanical inertia of the wind-turbine generator. As the grid voltage is recovered when the fault is cleared, the controller slows down the generator speed to the optimal speed. Fig.7 (b) shows that the proposal WECS supplies the grid with reactive current during the LVRT period and is able to redeliver controlled active power in a short time. The current during the grid fault is controlled deepening on the settings of the current limiter. Fig.7 (c) shows that the wind turbine torque decreased when the generator speed increased and during the grid fault. Fig.7 (d) shows that the grid power dropped to zero during the grid short circuit, and also Fig.7 (c) shows that when the grid voltage recovered the extra energy stored in the wind turbine inertia is transferred to electrical power and delivered to the grid. Fig .8 shows waveforms that summarize the performance of the proposed current limiter used in the LVRT technique. From Fig .8(a), the proposal LVRT technique succeeds in limiting the dc-link inductance current $I_{L}$ during the grid fault. Fig .8(b) shows the current in the LVRT resistance.

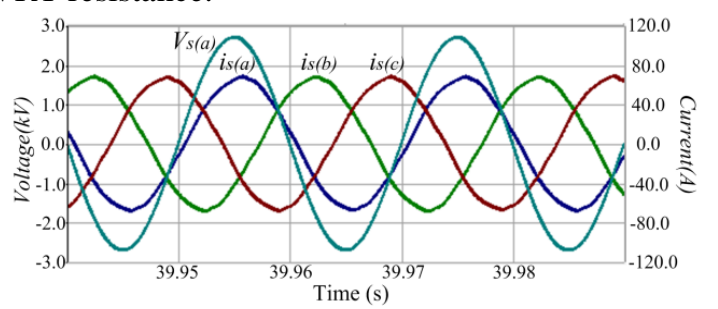

(a) The three phase grid current and phase ' $a$ ' voltage at $10 \mathrm{~m} / \mathrm{s}$ wind speed.

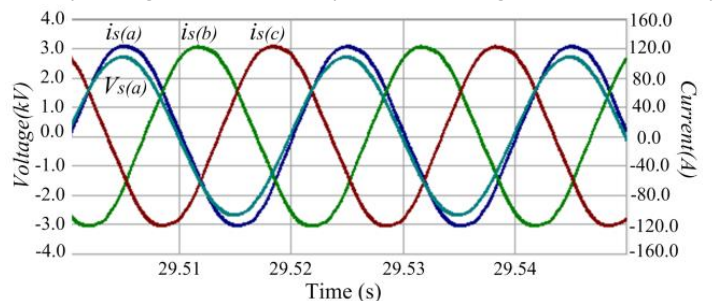

(b)The three phase grid current and phase ' $a$ ' voltage at $12.5 \mathrm{~m} / \mathrm{s}$ wind speed. Fig. 6 simulation results of grid current and phase 'a' voltage during different wind speed.

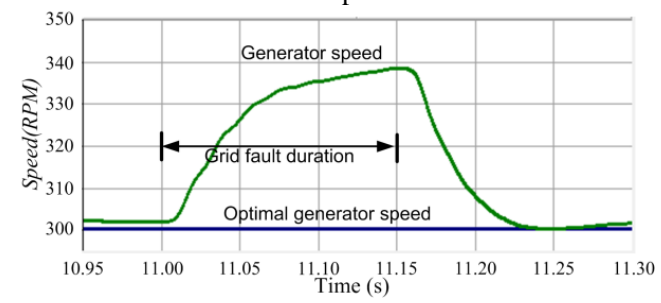

(a) Generator speed during grid fault and recovering

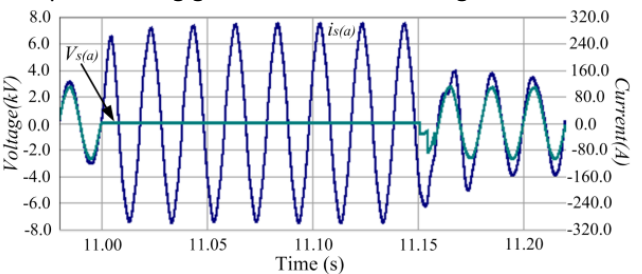

(b) Grid phases 'a' voltage and current during grid fault and recovering.

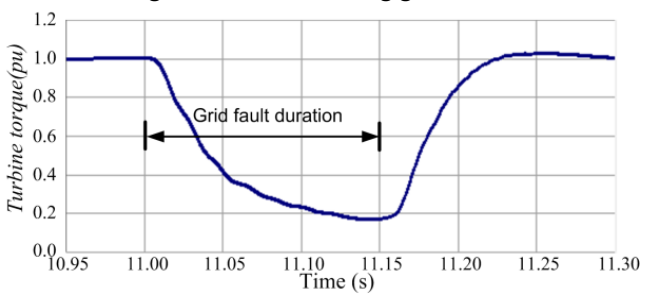

(c) Turbine tourque the grid fault and recovering in $\mathrm{pu}$

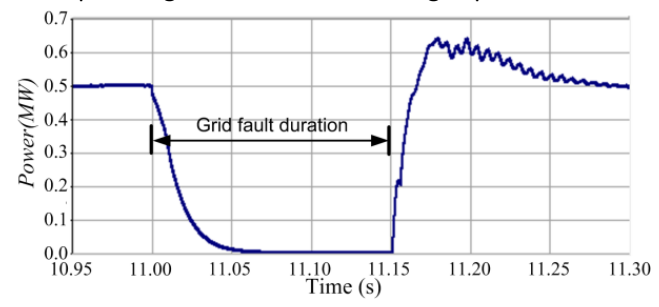

(d) Grid active power during grid fault and recovering.

Fig.7 waveforms show the overall performance of the proposal WECS during LVRT condition. 


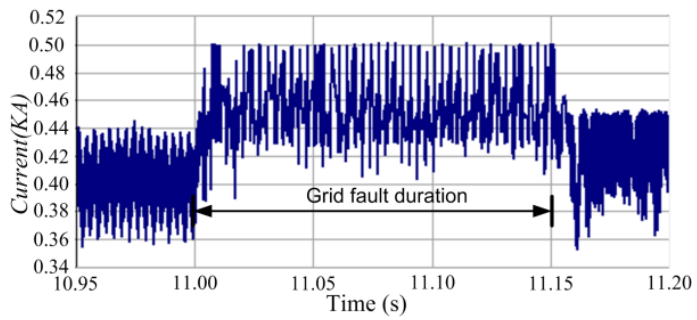

(a) dc-link inductance current during the grid fault

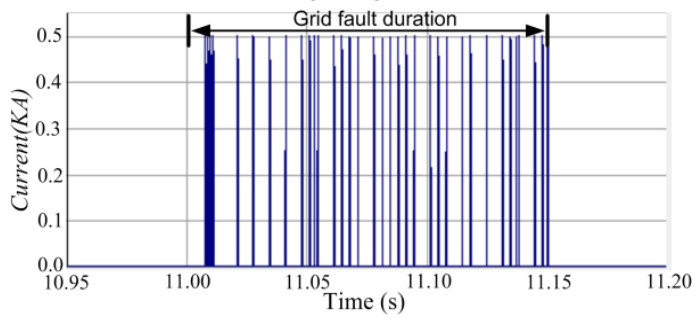

(b) LVRT resistance current during the grid fault.

Fig .8 Waveforms showing the dc-link current during a LVRT condition.

\section{EXPERIMENTAL RESULTS}

This section presents experimentally evaluation of the proposed WECS, with emphasis on its steady state and dynamic performance. The ability of the proposed WECS to track the MPPT is assessed by varying wind speed in four steps $(6 \mathrm{~m} / \mathrm{s}, 10 \mathrm{~m} / \mathrm{s}, 8 \mathrm{~m} / \mathrm{s}$ and $9 \mathrm{~m} / \mathrm{s})$; each step is maintained for 40s. The corresponding results are displayed in Fig. 9 and Fig .10. Fig. 9(a) shows the optimal speed and the generator speed, and active power the CSI delivers into the grid. The proposal controller tracks the optimal speed at different wind speeds, with minimum over/ under shoot, and with smooth active power changes delivered to the grid as the wind speed varies. Fig. 9(b) shows dc-link inductance current $I_{L}$, switch current $I_{S}$ and CSI dc input current $I_{i}$ at $8 \mathrm{~m} / \mathrm{s}$ wind speed. The dc-link inductance current $I_{L}$ equals the switch current when the switch $S_{r}$ in on and equals the CSI input current $I_{i}$ when the switch $S_{r}$ in off, as described in Section II. Fig. 9(c) shows the experimental waveform of the CSI output current $i_{i}$ is similar to the current waveform previously shown in Fig.2 (section II). Fig .10(a) and (b) show snapshots of the current the CSI injects into the grid and phase ' $a$ ' voltage, at $9 \mathrm{~m} / \mathrm{s}$ and $10 \mathrm{~m} / \mathrm{s}$ wind speed. Fig .10(a) and (b) show that the proposed WECS supplies power to the grid, with high quality sinusoidal current, and the proposed reactive power controller is able to regulate reactive power injection into the grid at zero. Fig .10 (c) and (d) show that the generator currents at $9 \mathrm{~m} / \mathrm{s}$ and $10 \mathrm{~m} / \mathrm{s}$ wind speed have different magnitudes and frequencies, as anticipated.

The simulation and experimental results presented in section III and IV show that the proposed BTB topology is suitable for wind energy conversion systems, as it allows proper system operation with a fixed frequency at the grid side and variable frequency at the generator side.

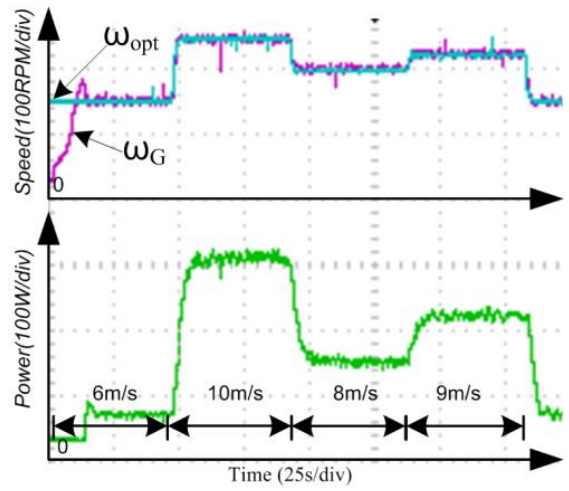

(a) Generator speed, optimal generator speed and grid output power during one full run of the proposed scenario.

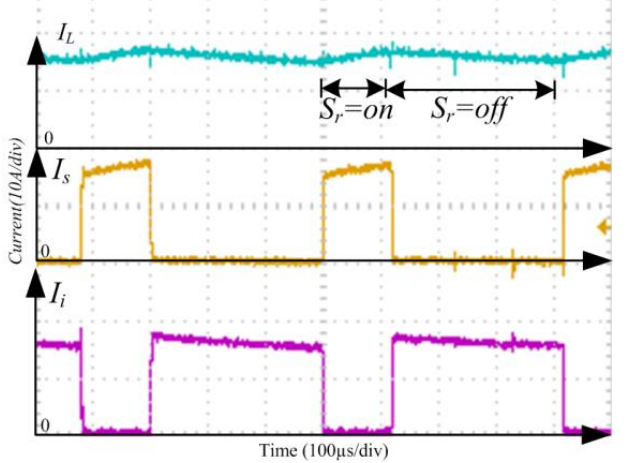

(b) dc-link inductance current $I_{L}$, switch current $I_{S}$ and CSI input current $\mathrm{I}_{\mathrm{i}}$ at $8 \mathrm{~m} / \mathrm{s}$ wind speed.

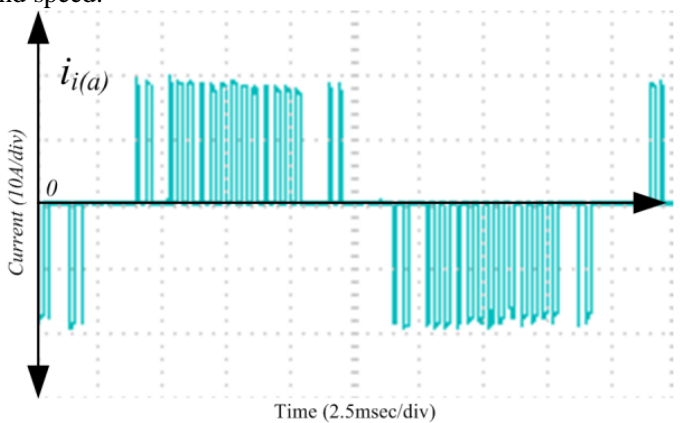

(c) CSI phase output current

Fig. 9 Waveforms showing the overall performance of the proposed wind energy conversion system.

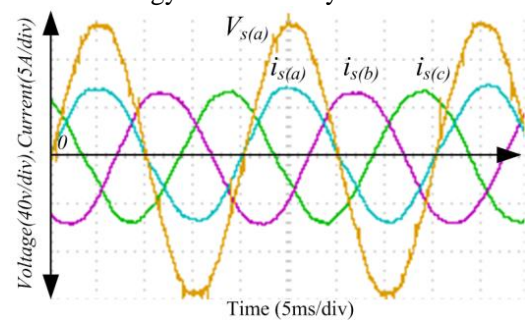

Three phase grid current and phase ' $a$ ' voltage, at $9 \mathrm{~m} / \mathrm{s}$ wind speed

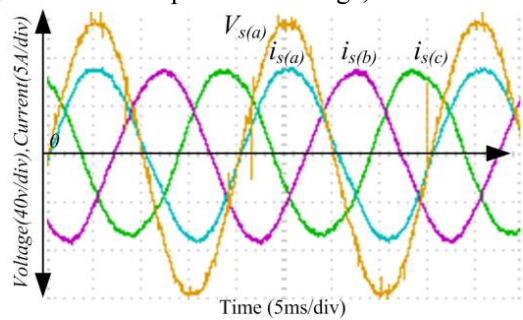

Three phase grid current and phase ' $a$ ' voltgae, at $10 \mathrm{~m} / \mathrm{s}$ wind speed. Fig .10 Detailed view of the gird side currents at $9 \mathrm{~m} / \mathrm{s}$ and $10 \mathrm{~m} / \mathrm{s}$. 


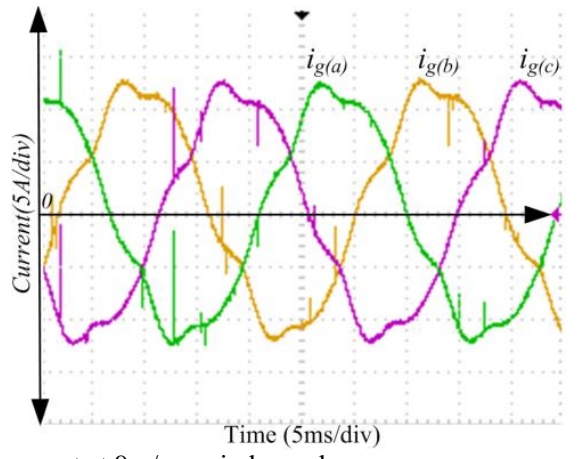

(c) Generator current at $9 \mathrm{~m} / \mathrm{sec}$ wind speed.

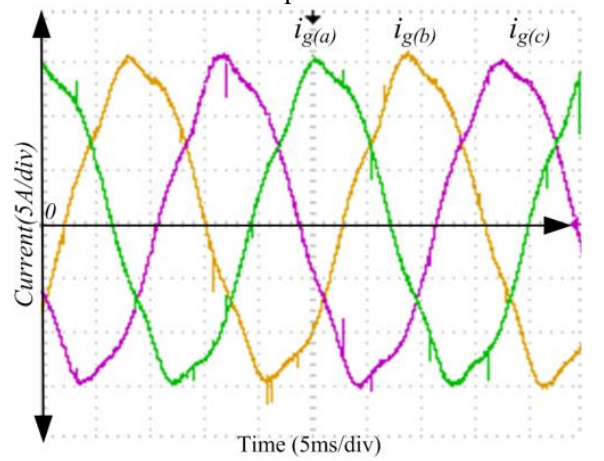

Time ( $5 \mathrm{~ms} / \mathrm{div})$

(d) Generator current at $10 \mathrm{~m} / \mathrm{sec}$ wind speed.

Fig.11 Detailed view of the generator currents at $9 \mathrm{~m} / \mathrm{s}$ and $10 \mathrm{~m} / \mathrm{s}$.

\section{CONCLUSION}

A new BTB current source converter topology and its application on variable speed WECS was presented. It has been shown that although the wind side converter supplies discontinues current to the input of the CSI bridge, the proposed arrangement is able to overcome the main drawbacks of the conventional CSI and offers several benefits. Some of the distinct features of the proposed BTB converter are the CSI switching devices are no longer exposed to frequent over-voltages during commutation as in a conventional CSI, and zero switching loss is achieved at the CSI side. Additionally, this paper presented a LVRT technique to enable WECS to ride-through severe ac network fault cases, with minimum impact on the wind generator drive train. The validity of the proposed WECS has been confirmed using EMTDC/PSCAD simulations, and experimental results from a scaled prototype.

\section{References}

Z. Shao, T. King-Jet, D. M. Vilathgamuwa, N. Trong Duy, and W. Xiao-Yu, "Design of a Robust Grid Interface System for PMSGBased Wind Turbine Generators," Industrial Electronics, IEEE Transactions on, vol. 58, pp. 316-328, 2011.

2] M. Singh and A. Chandra, "Application of Adaptive NetworkBased Fuzzy Inference System for Sensorless Control of PMSGBased Wind Turbine With Nonlinear-Load-Compensation Capabilities," Power Electronics, IEEE Transactions on, vol. 26, pp. 165-175, 2011.

[3] J. W. Kolar, T. Friedli, J. Rodriguez, and P. W. Wheeler, "Review of Three-Phase PWM AC-AC Converter Topologies," Industrial Electronics, IEEE Transactions on, vol. 58, pp. 4988-5006, 2011.
Power Coefficient Analysis of a New Maximum Power Point Tracking Technique," Industrial Electronics, IEEE Transactions on, vol. 60, pp. 1122-1132, 2013.

A. Sudhakaran and T. S. Angel, "Permanent magnet synchronous wind generator for microgrid dynamic performance improvement," in Emerging Research Areas and 2013 International Conference on Microelectronics, Communications and Renewable Energy (AICERA/ICMiCR), 2013 Annual International Conference on, 2013, pp. 1-6.

A. Mesbahi, A. Saad, M. Khafallah, O. Bouattane, and A. Raihani, "Boost converter analysis to optimise variable speed PMSG wind generation system," in Renewable and Sustainable Energy Conference (IRSEC), 2013 International, 2013, pp. 275-280.

O. Alizadeh and A. Yazdani, "A Strategy for Real Power Control in a Direct-Drive PMSG-Based Wind Energy Conversion System," Power Delivery, IEEE Transactions on, vol. 28, pp. 1297-1305, 2013.

J. M. Espi and J. Castello, "Wind Turbine Generation System With Optimized DC-Link Design and Control," Industrial Electronics, IEEE Transactions on, vol. 60, pp. 919-929, 2013.

M. Aner and E. Nowicki, "Two-level backward operation of a VSMC for PMSG grid-connected variable speed wind turbine systems," in Electric Machines \& Drives Conference (IEMDC), 2011 IEEE International, 2011, pp. 1100-1106.

Y. Guoliang and Z. Yanping, "Application of a matrix converter for PMSG wind turbine generation system," in Power Electronics for Distributed Generation Systems (PEDG), 2010 2nd IEEE International Symposium on, 2010, pp. 185-189.

L. Jun, S. Bhattacharya, and A. Q. Huang, "A New Nine-Level Active NPC (ANPC) Converter for Grid Connection of Large Wind Turbines for Distributed Generation," Power Electronics, IEEE Transactions on, vol. 26, pp. 961-972, 2011.

N. P. W. Strachan and D. Jovcic, "Stability of a Variable-Speed Permanent Magnet Wind Generator With Weak AC Grids," Power Delivery, IEEE Transactions on, vol. 25, pp. 2779-2788, 2010. D. Jingya, X. Dewei, and W. Bin, "A Novel Control Scheme for Current-Source-Converter-Based PMSG Wind Energy Conversion Systems," Power Electronics, IEEE Transactions on, vol. 24, pp. 963-972, 2009.

S. Zhou, J. Liu, L. Zhou, and Y. Zhu, "Improved DC-link voltage control of PMSG WECS based on feedback linearization under grid faults," in Applied Power Electronics Conference and Exposition (APEC), 2013 Twenty-Eighth Annual IEEE, 2013, pp. 2895-2899.

Q. keqing, J. Zhao, and X. Yuehong, "A LVRT control strategy based on DC-link voltage limit for PMSG wind generation system," in Power Electronics and Motion Control Conference (IPEMC), 2012 7th International, 2012, pp. 1169-1172.

S. Alepuz, A. Calle, S. Busquets-Monge, S. Kouro, and W. Bin, "Use of Stored Energy in PMSG Rotor Inertia for Low-Voltage Ride-Through in Back-to-Back NPC Converter-Based Wind Power Systems," Industrial Electronics, IEEE Transactions on, vol. 60, pp. 1787-1796, 2013.

A. D. Hansen and G. Michalke, "Multi-pole permanent magnet synchronous generator wind turbines' grid support capability in uninterrupted operation during grid faults," Renewable Power Generation, IET, vol. 3, pp. 333-348, 2009.

J. F. Conroy and R. Watson, "Low-voltage ride-through of a full converter wind turbine with permanent magnet generator," Renewable Power Generation, IET, vol. 1, pp. 182-189, 2007.

D. Jingya, X. Dewei, W. Bin, and N. R. Zargari, "Unified DC-Link Current Control for Low-Voltage Ride-Through in CurrentSource-Converter-Based Wind Energy Conversion Systems," Power Electronics, IEEE Transactions on, vol. 26, pp. 288-297, 2011.

B. Wu, High-Power Converters and AC Drives: Wiley, 2006.

L. Barote, C. Marinescu, and M. N. Cirstea, "Control Structure for Single-Phase Stand-Alone Wind-Based Energy Sources," Industrial Electronics, IEEE Transactions on, vol. 60, pp. 764-772, 2013.

L. Shuhui, T. A. Haskew, R. P. Swatloski, and W. Gathings, "Optimal and Direct-Current Vector Control of Direct-Driven PMSG Wind Turbines," Power Electronics, IEEE Transactions on, vol. 27, pp. 2325-2337, 2012.

S. Nishikata and F. Tatsuta, "A New Interconnecting Method for 
Wind Turbine/Generators in a Wind Farm and Basic Performances of the Integrated System," Industrial Electronics, IEEE Transactions on, vol. 57, pp. 468-475, 2010.

[24] M. Pucci and M. Cirrincione, "Neural MPPT Control of Wind Generators With Induction Machines Without Speed Sensors," Industrial Electronics, IEEE Transactions on, vol. 58, pp. 37-47, 2011.

[25] D. G. Holmes and T. A. Lipo, Pulse Width Modulation for Power Converters: Principles and Practice: John Wiley \& Sons, 2003. 